\title{
A PEDAGOGIA UNIVERSITÁRIA DO BACHAREL DOCENTE NA GRADUAÇÃO EM CIÊNCIAS CONTÁBEIS
}

\author{
Tatiana Rosa Carvalho Ribeiro ${ }^{1}$ \\ https://orcid.org/0000-0003-0722-988X
}

Loriége Pessoa Bitencourt ${ }^{2}$ http://orcid.org/0000-0002-7643-2091

RESUMO: A pesquisa da qual se originou este artigo teve como objetivo principal compreender o modo com que a formação do bacharel docente do curso de Ciências Contábeis (BDCC) de uma universidade pública do estado de Mato Grosso e as atividades docentes desenvolvidas no curso contribuem para a pedagogia universitária. Trata-se de uma pesquisa com abordagem qualitativa do tipo estudo de caso. Os instrumentos de coleta de dados foram: questionário de caracterização e entrevista semiestruturada. Os sujeitos foram sete docentes efetivos, selecionados a partir de critérios definidos. Os dados revelaram que os BDCC estão em constante formação nas áreas específicas, buscando inovações e melhorias de suas práticas educativas. Referente às atividades desenvolvidas, o ensino recebeu maior destaque, ficando em segundo lugar a extensão, por Ihes proporcionar satisfação e considerá-la uma prestação de serviços à comunidade e, por último, constatou-se que a atividade de pesquisa é desenvolvida de maneira periférica pelos sujeitos.

PALAVRAS-CHAVE: Pedagogia universitária. Docência na educação superior. Bacharel docente.

\section{THE UNIVERSITY PEDAGOGY OF THE BACHELOR TEACHER IN THE COURSE OF ACCOUNTING SCIENCES}

ABSTRACT: The research that gave origin to this article had the main objective of understanding how the education of the bachelor teacher in the degree in Accounting Sciences (BTAS) of a public university from the state of Mato Grosso and teaching activities developed in the course contribute for the university pedagogy. It is about a research of qualitative approach of the case study type. The instruments to collect the data were the characterization questionnaire and the semi-structured interview. The subjects comprised seven active teachers selected by defined criteria. The data disclosed that BTASs are in constant training in specific fields in the search

1 Mestra Em Educação Profissional Técnica da Educação Superior - Universidade do Estado de Mato Grosso (UNEMAT) Cáceres, Mato Grosso, Brasil. tatiana.ribeiro@unemat.br

2 Doutora em Educação. Professora da Educação Superior - Universidade do Estado de Mato (UNEMAT), Cáceres, Mato Grosso, Brasil. lori.pessoa@hotmail.com 
for innovation and aiming to improve their educational pedagogies. Regarding the developed activities, teaching was given the greatest emphasis and in the second position came the extension because it provides satisfaction and they consider that it renders services to the community and lastly it has been found out that the research activity is developed in a peripheral way by the subjects.

KEY WORDS: University Pedagogy. Teaching in High Education. Bachelor Teacher.

\section{LA PEDAGOGÍA UNIVERSITARIA DEL LICENCIADO DOCENTE EN LA GRADUACIÓN EN CIENCIAS CONTABLES}

RESUMEN: La investigación que dio origen a este artículo tuvo el objetivo principal de comprender el modo como la formación del licenciado docente en la carrera de Ciencias Contables (LDCC) de una universidad pública del Estado de Mato Grosso y las actividades de la docencia desarrolladas en el curso contribuyen para la pedagogía universitaria. Se trata de una investigación de enfoque cualitativo del tipo estudio de caso. Los instrumentos para recolección de los datos fueron el cuestionario de caracterización y la entrevista semiestructurada. Los sujetos conformaron siete docentes efectivos, elegidos desde criterios definidos. Los datos han revelado que los LDCCs están en constante capacitación en áreas específicas buscando innovaciones y el perfeccionamiento de sus prácticas educativas. Concerniente a las actividades desarrolladas, la enseñanza recibió el mayor relieve, quedando la extensión en el segundo lugar porque les proporciona satisfacción y la consideran una prestación de servicios a la comunidad y, por último, se ha constatado que la actividad de investigación se desarrolla de modo periférico por los sujetos.

PALABRAS-CLAVE: Pedagogía Universitaria. Docencia en la Educación Superior. Licenciado Docente 


\section{Introdução}

Apresentamos, neste artigo, os resultados de uma pesquisa sobre a formação e as atividades na docência, desenvolvida por bacharéis docentes em Ciências Contábeis (BDCC) de uma universidade pública estadual de Mato Grosso, em um dos seus campi. Nesta pesquisa tivemos o objetivo de compreender o modo com que a formação do bacharel docente do curso de Ciências Contábeis e as atividades docentes desenvolvidas no curso contribuem para a pedagogia universitária.

Neste sentido, enfatizamos nosso objeto de pesquisa, a Pedagogia Universitária, que representa a junção de dois termos com grande peso no âmbito educacional, porém ganhando um sentido único (ARAÚJO, 2008). Destacamos que esta se distingue da pedagogia geral, pois o interesse está em compreender a aprendizagem na fase adulta das pessoas.

Assim, conceituamos Pedagogia Universitária partir de alguns autores Bitencourt (2014); Leite (2006); Cunha (2010) e Couto (2013), como um campo de pesquisa e de prática que se interessa pelo processo de formação pedagógica e pelas atividades a serem desenvolvidas na docência universitária.

Esta investigação advém de inquietações relacionadas à formação necessária para o docente universitário, voltando nosso olhar ao profissional liberal que escolhe a docência na educação superior como profissão, buscando, assim, entender quais atividades lhes são inerentes.

Ressaltamos que nosso olhar está centrado na universidade, um dos espaços em que a pedagogia universitária, como campo de estudos e prática, tem sido consolidada, considerando todo o processo que a educação superior passou desde a década de 1990, com a expansão e democratização do acesso desse nível formativo.

Desse modo, estruturamos o artigo de modo a apresentar uma síntese do referencial teórico que embasou nossa pesquisa; a descrever o caminho metodológico percorrido e apresentar os dados, a análise e interpretação como forma de responder nossa problemática. E, por fim, nossas considerações, em que deixamos clara a convicção de ser um tema que não se esgota nesta investigação, e sim abre caminho para a construção da Pedagogia Universitária não só nos cursos de bacharelados. 


\title{
Pedagogia Universitária e o bacharel docente em ciências contábeis
}

Nossa construção teórica foi delineada de forma a apresentar o cenário específico e foco de investigação, em que partimos da dimensão maior, a Educação Superior, que engloba todas as discussões e conceitos de relevância para o estudo, enfatizando a docência exercida pelos BDCCs.

Cabe enfatizar que o foco deste estudo foi uma universidade pública, considerada um

\begin{abstract}
[...] espaço de diálogo, de formação e de produção de conhecimento, necessita rever suas ações institucionais a fim de promover ensino qualificado, adequado aos novos públicos, pois os grupos de hoje presentes no segmento universitário estão cada vez mais diversos e distintos dos anos anteriores (BITENCOURT, 2014, p.104).
\end{abstract}

Dessa maneira, faz-se imprescindível adequações aos novos perfis de estudantes e de um docente universitário atualizado e contextualizado com este público heterogêneo, devendo estar apto a desenvolver suas atividades, englobando as novas exigências dadas à essa profissão. Cabe salientar que a universidade é confrontada diariamente em relação à sua capacidade de formar profissionais, pois vivemos em uma sociedade em constante transformação.

Assim, inserimos outra dimensão importante para a reflexão, a pedagogia universitária, como um campo que vem se consolidando na busca de melhorias e inovações da prática da docência na educação superior, "um movimento dinâmico preocupado com a formação docente", conforme preceitua Bitencourt (2014, p. 108), entendido como campo do conhecimento polissêmico, que envolve estudos sobre uma pedagogia voltada para a educação superior, em crescente expansão.

Para Cunha (2010), a Pedagogia Universitária vem se expandindo como objeto de reflexões e de práticas no contexto da educação brasileira. Essa autora ressalta que as políticas educacionais no país foram direcionadas, por meio de uma energia democratizadora, nos meados da década de 1980, configurando um discurso voltado às políticas sociais e com a premissa da necessidade de a universidade manter a indissociabilidade entre ensino, pesquisa e extensão, como forma de superar a pedagogia tradicional.

Nesse contexto, a Pedagogia Universitária se distingue da pedagogia geral quanto ao interesse em compreender a aprendizagem na fase adulta das pessoas e em sua trajetória de formação profissional (SAVIANI, 2011), cha- 
mando a atenção para o fato de que esse campo se preocupa com a formação e o exercício da docência na educação superior, e como uma das maneiras encontradas para ampliar discussões relacionadas à inserção de inovações didáticas e o uso de tecnologias para garantir melhorias à prática docente de nível superior, sendo que a maioria dos estudos, desta área, destaca a urgência de se formar pedagogicamente o professor (FRANCO; KRAHE, 2003; LEITE, 2006; SOARES; CUNHA, 2010; COUTO, 2013).

Desse modo, buscamos conceituar Pedagogia Universitária dentre os autores citados e grupos de estudos e pesquisas que discutem essa temática, na qual percebemos que a concebem como um campo de pesquisa e de prática que se interessa pelo processo de formação pedagógica e pelas atividades desenvolvidas na docência universitária.

Nesse âmbito, concordamos com Couto (2013, p. 49) quando afirma que a pedagogia

[...] dará fundamentação para que o professor universitário reflita sobre o projeto da instituição na qual atua, o projeto do(s) curso(s) em que leciona, a função do processo ensino-aprendizagem que desenvolve, o perfil dos alunos que recebe em suas aulas, as formas de avaliação condizentes com a proposta institucional e de curso, etc.

E, desse modo, poderá trazer subsídios da ciência da educação para fundamentar a ação dos profissionais que lidam com a formação de indivíduos de maneira a prepará-los para a vida, como emancipação e em um processo permanente. Couto (2013) reforça esse pensamento ao salientar que a Pedagogia Universitária pode auxiliar o docente universitário a estabelecer um vínculo identitário com a profissão docente pelo simples fato de o docente assumir que, juntamente com o ensino, também assume ser pesquisador e/ ou extensionista e, ao mesmo tempo, um profissional de sua área (arquiteto, economista, nutricionista, etc.). Isso já é, essencialmente, ser um docente, afirma a autora, enfatizando que sem construir uma identidade com a profissão docente, torna-se difícil a busca de uma formação com viés pedagógico por parte desse profissional.

Volpato (2010) corrobora com essa concepção ao destacar que a constituição identitária de uma profissão vai se estruturando durante o período de formação acadêmica e profissional, e em se tratando dos profissionais liberais que atuam como docentes universitários, esse período é insuficiente para uma reflexão contextualizada sobre a nova profissão que passam a exercer. 
O processo de construção identitária deve ser contínuo e permanente, sendo extremamente importante para que o docente se reconheça como um profissional da Educação e possa desenvolver a Pedagogia Universitária de forma responsável e conhecendo seu campo de atuação, o que lhe permitirá a construção de conhecimentos e o direito à criticidade (ROVEDA; MIOLO, 2017).

Roveda e Miolo (2017, p. 72) conceituam a identidade profissional docente como um "processo de construção, reconstrução, transformação de referenciais que dinamizam a profissão de professor", que consideramos ser um movimento constante, sempre inconcluso, que se repete ao longo da trajetória de vida pessoal e profissional de cada docente. Isto porque, na condição de seres humanos, os docentes estão sempre revisando, trabalhando em diferentes contextos e, em cada semestre, encontram perfis diferenciados de estudantes que exigem desse docente capacidade adaptativa para estar sempre se construindo e refletindo se deve ou não continuar com determinada prática.

Nesse sentido, ao construir uma identidade docente, o profissional liberal passa a entender a docência como uma atividade que tem um ser humano como seu objeto de trabalho, que se realiza em um processo em que o docente também aprende ao ensinar (TARDIF, 2007).

Dialogando com os estudiosos, consideramos importante conceituar docência como uma atividade realizada mediante interações humanas, entre professores com alunos, e os outros sujeitos pedagógicos, como os outros docentes, técnicos administrativos, coordenadores (BITENCOURT; ZART, 2017).

Assim, entendemos imprescindível estudar o bacharel docente, considerando sua formação técnica, profissional e pessoal, pois, conforme relata Volpato (2010), os docentes, devem ser vistos como seres humanos, individualizados e socializados ao mesmo tempo, que estabelecem relações ao desenvolver o trabalho docente, por meio de relações humanas que são individuais e sociais.

Para o embasamento de nossa pesquisa contamos também com resultados da pesquisa realizada por Vasconcelos (2009, p. 24) que define o profissional liberal-professor como "aquele indivíduo que, tendo uma profissão, e exercendo-a, decide acrescentar às suas atividades profissionais a docência num determinado curso superior, em tempo parcial de dedicação". No caso investigado neste estudo, os BDCCs habilitam-se na profissão de contador e, portanto, sem formação inicial para o exercício profissional de docente.

Semelhante a outras carreiras liberais, o contador se tornou um profissional com funções ampliadas. Desde a criação do curso superior de Ciências Contábeis, em 1951, a Contabilidade, como ciência presente no cotidiano 
social, vem se alterando, acompanhando as mudanças no cenário mundial, ajustando suas normas e as características do profissional contábil (SOUZA; MENDONÇA, 2016).

Segundo Laffin (2005), a Contabilidade é a área de conhecimento que lida com o patrimônio das pessoas, e o Contador necessita de um amplo conhecimento do contexto social e concepção de mundo para trabalhar as informações relevantes ao bom andamento das empresas. Em que reforçamos o momento de globalização às normas internacionais de contabilidade que também refletiram no ensino e aprendizagem desse novo profissional contábil.

Gonçalves e Gasparin (2013) relatam que alguns desses bacharéis docentes foram motivados para atuar na docência a partir de alguns aspectos, entre os quais: o interesse pela área de ensino, o desejo de contribuir para com a educação e, ainda, o recebimento de convites para atuarem como docentes. Os resultados da pesquisa realizada pelos autores citados demonstram que a maioria, baseia-se nos professores da graduação, na troca de materiais e práticas entre colegas da mesma área.

Com isso, mesmo não possuindo formação voltada para a tarefa de ensinar, os autores supracitados, explicitam que o bacharel se constitui e se faz docente no cotidiano da prática, aprendendo a ensinar na vivência do magistério. Sendo clara a necessidade de uma formação permanente e contínua do professor de contabilidade, como destaca Nossa (1999, p. 7), enfatizando que este "deve ter conhecimentos técnicos da Contabilidade e de áreas afins, de metodologia de ensino, de cultura geral e aptidões sociais".

Dessa maneira, entendemos que os BDCCs precisam adquirir uma formação polivalente baseada em amplos conhecimentos para o desenvolvimento de sua autonomia e que aprendam a aprender. Para tanto, entendemos que a preocupação de estar em constante atualização não deve partir somente do docente, mas da universidade, possibilitando bases estruturais para o desenvolvimento das atividades de ensino, pesquisa e extensão ao seu corpo docente, contribuindo para que os docentes construam novos conhecimentos; realizem novas pesquisas; participem de eventos, congressos, cursos, entre outros meios de atualização, e também possam ter condições de realizar produções científicas, enraizando um interesse de busca permanente de aprender (VASCONCELOS, 2009).

As discussões e conceitos destacados até aqui retratam nosso movimento de aproximação com o campo de investigação que envolveu desdobramentos que contornam a educação superior: a pedagogia, como ciência norteadora da educação; a universidade, como lócus da realização da mesma; 
a docência universitária, que configura o trabalho realizado por profissionais liberais das mais diversas áreas, na qual decidimos enfatizar os BDCCs.

\section{A formação e as atividades na docência universitária}

Complementando o aprofundamento teórico, buscamos entender como está configurada a formação do docente universitário. Para tanto, nos embasamos em alguns autores: Marcelo Garcia (1999), Imbernón (2002), Bitencourt (2017), Freire (1996), entre outros, e a partir deles consideramos formação um processo de constante e contínua busca por conhecimentos, que inicia-se muito antes da graduação, pois cada indivíduo traz consigo experiências vividas em espaços formais ou informais, que influenciam, de certo modo, o seu processo formativo e profissional.

A formação docente no contexto atual, para Imbernón (2002) e Bitencourt (2017), deve ser capaz de preparar o docente de forma permanente, concebendo-a como um processo contínuo que perpassa toda trajetória profissional. Desse modo, assumimos o conceito de formação docente como um processo multifacetado de construção e de desenvolvimento que se mantém em movimento permanente de inconclusão. Compreendemos que essa formação é realizada no exercício diário e ao longo do tempo, podendo trazer mudanças significativas no sentido de o docente perceber a necessidade de estar sempre aprendendo ao ensinar e vice-versa.

No caso específico do curso de bacharelado em ciências contábeis, que se destina à preparação do profissional contábil e não à carreira docente e, partindo-se do pressuposto de que a maioria dos professores que se dedicam ao ensino contábil tem sua formação inicial (graduação) nesse curso, consequentemente não possuem formação acadêmica ou profissional direcionada ao exercício do magistério superior. Assim, a primeira etapa de formação acadêmica para esse docente universitário, declara Andere (2007), são os cursos de pós-graduação stricto sensu (mestrado/doutorado), considerada uma etapa madura na carreira desse docente, em que se estabelece uma acentuada dedicação à pesquisa e um amplo domínio do campo ao qual o pesquisador se dedica, habilitando-o a conduzir uma investigação original.

No entendimento de Nossa (1999, p. 65), nesses cursos de pós-graduação "dá-se muita ênfase à pesquisa e ao estudo de determinados assuntos específicos, ficando, por vezes, prejudicado o aprendizado pedagógico daqueles que seguem ou pretendem seguir a carreira docente". Desse modo, a maioria dos cursos não enfatizam discussões voltadas ao ensino universitário, uma das 
atividades que constituem essa profissão.

Assim, enfatizamos a necessidade de uma formação que ultrapasse a simples atualização profissional e considere as trocas realizadas de maneira informal, seja no convívio diário com outros bacharéis docentes, nas observações no meio acadêmico e institucional, ou pela leitura e reflexões sobre sua própria prática pedagógica (LAPINI, 2012), na qual o BDCC vai se formando em sua trajetória profissional. E isso ocorre por meio da vivência de diversos processos formativos, como ser humano que está em constante adaptação no contexto que o cerca, ao longo de sua trajetória pessoal e profissional, em uma constante apropriação de saberes e fazeres próprios, pois, atuando na docência, esse professor forma seus estudantes e também se forma, ou seja, constitui-se docente (ISAIA, 2006).

Um dos maiores desafios na formação profissional ou pedagógica é o interesse do docente em refletir sobre a necessidade e a capacidade de "ultrapassar o paradigma conservador baseado na reprodução do conhecimento, na repetição e na memorização", como enfatiza Behrens (2011, p. 446), enraizado, assim, na ação docente. $O$ ato de buscar inovação para uma ação mais transformadora se faz urgente, pois essa formação deve perpassar o docente, se entranhar em suas conviç̧ões de maneira que ele possa se convencer da necessidade de alterar sua prática. Caso contrário, ele retomará suas aulas com a mesma abordagem que o acompanhou durante toda sua carreira docente (BEHRENS, 2011).

Segundo os estudos de Behrens (2011), o bacharel docente é um dos perfis que integram os profissionais que atuam nas universidades em tempo integral ou atuam como profissionais liberais, associando um tempo parcial à docência. Conforme a autora, a maioria deles está no segundo perfil nas IES privadas, e a autora arrisca-se a dizer que nas IES públicas isso também está acontecendo pelo fato de a profissão contábil possibilitar maior remuneração.

Consideramos ser necessário que o BDCC, ao optar pela docência universitária, tenha consciência de que o papel desempenhado em sala de aula é, essencialmente, o de docente e não de contador. Para que isso ocorra, Cunha (1996) destaca ser necessária a superação de crenças baseadas nas premissas de que para ser docente basta ser um bom profissional em sua área, ou para ensinar basta saber o conteúdo.

\section{Caminho metodológico}

Para alcançar o objetivo desta pesquisa optamos pela abordagem 
qualitativa, por proporcionar uma compreensão aprofundada de um grupo social e, conforme Bodgan e Biklen (1994), possibilitar a descrição de dados que revelam o modo de pensar dos sujeitos investigados.

A pesquisa, do tipo Estudo de Caso, segundo Yin (2010), visa estudar as características de um grupo ou fenômeno, de forma particular, fazendo-se necessária a delimitação do caso, que Lüdke e André (1986) destacam ser uma unidade dentro de um sistema mais amplo, com contornos claros e suas especificidades. As autoras enfatizam que esse tipo de pesquisa pode trazer a interpretação de um contexto, as relações e percepções das pessoas ligadas a uma situação específica, tornando-se complexo e profundo justamente por buscar retratar a realidade em determinado contexto.

O caso estudado foi a Pedagogia Universitária do BDCC de uma IES pública estadual de Mato Grosso, em que definimos os sujeitos da pesquisa, utilizando quatro critérios de seleção ${ }^{3}$, cujo universo possuía um total de 32 docentes universitários (efetivos e contratados), conforme lotacionograma do quadro docente do curso de Ciências Contábeis - semestre 2016/2. Ao inserir os

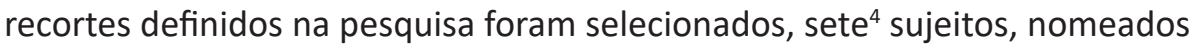
respectivamente de BDCC1, BDCC2, BDCC4, BDCC5, BDCC6, BDCC7 e BDCC8.

$O$ plano de pesquisa foi realizado em quatro momentos distintos: pesquisa bibliográfica, documental, de campo e a análise dos dados. Para a coleta dos dados utilizamos um questionário de caracterização (QC) on-line, por meio da ferramenta do GoogleForms, complementado por uma entrevista (FONSECA, 2002).

Para a análise dos dados utilizamos a técnica de análise de conteúdo, definida por Bardin (2006, p. 38) como "um conjunto de técnicas de análise das comunicações, que utiliza procedimentos sistemáticos e objetivos de descrição do conteúdo das mensagens", complementando-a com o software NVivo11, que gerou nuvens de termos que mais se repetem nas falas dos sujeitos.

Ressaltamos que as categorias de análise emergiram conforme nossa interpretação e criatividade, relacionando-as ao referencial teórico construído e às respostas obtidas nos dados coletados.

3 Critérios de seleção: ser docente efetivo na carreira docente da educação Superior; ser graduado em ciências contábeis em qualquer IES; estar lotado na faculdade de Ciências Sociais e Aplicadas e ter ministrado disciplinas no semestre letivo 2016/2 - em efetivo exercício.

4 Selecionamos 8 BDDCs nomeados BDCC de 01 a 08, da qual excluiu-se o BDCC3, pois não retornou ao primeiro instrumento de coleta de dados, o questionário. 


\section{Resultados e discussões}

A análise dos dados, para esse recorte, foi realizada a partir das categorias temáticas: o perfil, a trajetória de formação e as atividades na docência.

\section{Perfil dos BDCCs da IES pesquisada}

Inicialmente, buscamos conhecer quem eram os sujeitos da pesquisa - caracterização do perfil - levando em consideração a formação inicial e a acadêmica, e o regime de trabalho, a partir dos dados coletados no QC e na entrevista.

Assim, no grupo pesquisado, os dados revelaram o predomínio do gênero masculino, sendo seis homens e uma mulher, confirmando uma das características da profissão contábil, evidenciada pela pesquisa de Laffin (2002). Em relação à faixa etária, seis BDCCs têm idade entre 30 e 45 anos, e um BDCC tem 65 anos, revelando um grupo relativamente jovem, correlacionando com pesquisa realizada por Slomski et al. (2008) e com o perfil traçado pelo Censo da Educação Superior (BRASIL, 2016).

Em relação ao tempo de efetivação no cargo de professor da Educação Superior, cinco efetivaram-se em 2006, tendo como tempo de atuação na docência universitária, em sua maioria, entre 10 a 15 anos, considerando o tempo trabalhado na condição de docente interino. Sob este aspecto, reafirmamos que a docência esta inserida em um movimento em que o docente aprende ao ensinar, nas trocas de experiências e nas interações experimentadas ao longo do exercício profissional (BITENCOURT, 2014; TARDIF, 2007; PIMENTA; ANASTASIOU, 2008; VASCONCELOS, 2009).

Foi possível verificar que o perfil dos BDCCs, sujeitos participantes desta pesquisa, quanto à maior titulação, diferencia-se do traçado pelo Censo da Educação Superior de 2016, pois o grupo pesquisado possui seis mestres e um especialista, e até aquele momento da pesquisa nenhum doutor. No entanto, quanto ao enquadramento do regime de trabalho, o grupo apresentou semelhanças, pois cinco BDCCs (1, 2, 5, 6 e 7) enquadram-se em Tempo Integral - Dedicação Exclusiva (TIDE), conforme preceitua o artigo 14 da Lei Complementar no 320/2008, e somente os BDCCs 4 e 8 desenvolvem suas atividades em Tempo Parcial (TP), e são os únicos que exercem, além da docência universitária, a profissão de contador. 


\section{Trajetórias de Formação}

Ao analisar as trajetórias formativas dos BDCCs - formação acadêmica (graduação e pós-graduação) e profissional (docentes universitários) - refletimos sobre as significações constituídas pelos sujeitos no seu desenvolvimento profissional.

Ribeiro (2018) constatou que em relação à formação acadêmica na graduação, dos sete sujeitos investigados, quatro ${ }^{5}$ graduaram-se no curso de Ciências Contábeis da mesma IES pesquisada, onde, na época, eram docentes. Quando questionamos sobre o porquê da escolha do curso de graduação em Ciências Contábeis, constatamos uma diversidade de fatores que pode tê-los influenciado

Figura 1 - Nuvem de Palavras - Respostas Q1 - Escolha do Curso

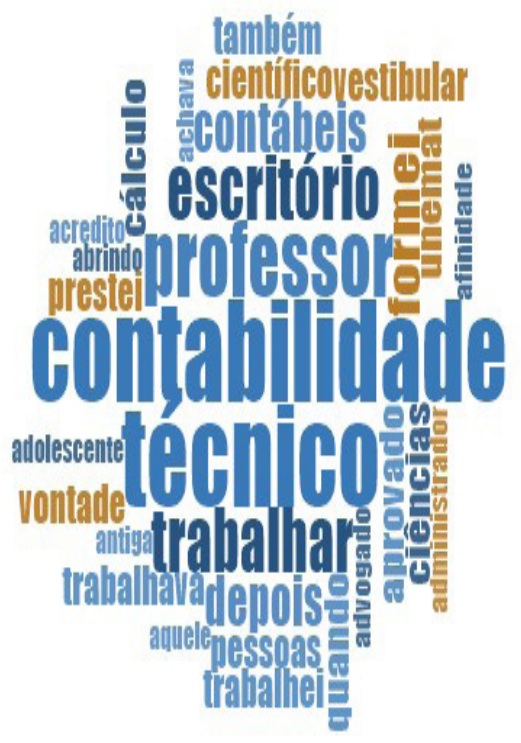

Fonte: Elaborado pela autora, 2017.

Como observamos na nuvem de palavras gerada a partir das falas dos sujeitos, o termo de maior expressão é técnico em contabilidade, em que relacionamos a escolha ter sido associada a sequência/continuidade do curso de nível técnico, pois os BDCCs 4, 6 e 7 realizaram este curso. Os demais

5 Os BDCCs egressos do curso de Ciências Contábeis da IES pesquisada são: BDCC 1, BDCC 2, BDCC5 e BDCC6. 
sujeitos, relacionam sua escolha à afinidade e ao desejo de trabalhar em escritórios, característica intrínseca à profissão contábil, e por já estarem atuando nesses locais. Desse modo, inferimos que a formação técnica, as experiências em atividades profissionais no ramo contábil foram elementos que os BDCCs consideraram para a escolha de sua formação inicial (FERREIRA, 2015; BITENCOURT, 2017).

Um dos sujeitos participantes da pesquisa, o BDCC 6, em sua fala demonstrou o desejo de tornar-se docente muito antes de sua escolha pelo curso, pois já era professor no Ensino Médio, quando, segundo Bitencourt (2017), as experiências pré-profissionais podem tê-lo influenciado profissionalmente, levando-o a perceber a possibilidade de atuar na universidade após a graduação em ciências contábeis.

Em relação à formação acadêmica na pós-graduação, todos os sujeitos da pesquisa cursaram especialização, e seis deles, mestrado, predominando os cursos nas áreas específicas e afins da contabilidade. Esse achado se alinha aos resultados encontrados por Ferreira (2015), Lapini (2012), Andere e Araújo (2008) de que isso se deve ao fato de os docentes enxergarem, nesses cursos, a possibilidade de aprofundar conhecimentos específicos da área contábil que trariam contribuições relacionadas à prática docente e na didática apreendida.

Apresentamos as respostas dadas por alguns sujeitos na entrevista referente à questão 23 , sobre escolha de pós-graduações nas linhas específica da área contábil:

[...] é mais para fortalecer essa [...] relação com a pesquisa na área contábil, e, consequentemente, também fortalecer a parte pedagógica e metodológica também nas Ciências Contábeis. (BDCC 1)

[...] escolhi pela área que eu [...] trabalhava em sala de aula, [...] que contribuiu muito [...]. Eu aprendi muito mais coisas. (BDCC 2) Surgiu por questão profissional mesmo, e como as disciplinas que eu ministrava estavam relacionadas também. (BDCC 4)

Primeiro pela qualificação como professor [...] para entender melhor a situação do aluno, o processo de aprendizagem, [...] naquele momento eu não era apenas contador, eu era professor, [...] precisava me aperfeiçoar como professor. (BDCC 7)

Assim, podemos considerar que os dados coletados alinham-se aos estudos de Ferreira (2015) e Lapini (2012), quando afirmam que a opção por 
cursos na área contábil e afins refere-se à busca por aprofundamento dos conhecimentos específicos de contabilidade, e também uma forma de iniciar a produção de pesquisas nessa área. Diante dos excertos transcritos acima, inferimos que houve contribuições para a prática desses docentes, mesmo sendo programas de pós-graduação nas áreas específicas, o que consideramos uma forma de potencializar a docência desenvolvida por eles, contribuindo, portanto, para a Pedagogia Universitária atualizada e contextualizada no curso pesquisado.

Os BDCCs também enfatizam a necessidade de estar em constante formação, principalmente pela profissão contábil se inserir em um contexto que se altera do dia para a noite, percebendo a conscientização da necessidade de formação contínua, como evidencia o relato do BDCC 7,

\begin{abstract}
[...] eu senti que faltava [...] a formação, que é aquela quando você faz um curso de pedagogia, letras, história ou geografia, estes te formam para ser professor. O curso de bacharel em Ciências Contábeis não te forma para ser professor, te forma para ser contador. [...] Então eu fui fazer [...] Psicopedagogia, que [...] me ajudou [...] como professor [...] foi essencial para minha carreira. (BDCC 7)
\end{abstract}

Nesse trecho, fica evidente a conscientização de estar buscando formação para suprir deficiências encontradas ao escolher a profissão de docente. Essa percepção, conforme Volpato (2010) relata, é um movimento necessário no exercício da profissão docente, bem como seria no exercício da atividade contábil, pois é imprescindível o aperfeiçoamento contínuo em todas as profissões.

Ainda sob esse aspecto, o BDCC 5, revela que na especialização em contabilidade pública, participou de uma disciplina de didática do ensino superior que contribuiu para melhorar sua prática, pois "[...] nela havia seminários que a gente tinha que apresentar uma aula". E o BDCC 6, que cursou mestrado em Ciências Sociais, afirma que havia uma disciplina que "você preparava uma aula". Portanto, mesmo sendo uma pós-graduação na área específica, havia uma disciplina de cunho pedagógico, porém, Pimenta e Anastasiou (2008), Coimbra e Felício (2015) ressaltam não ser suficiente para o preparo do docente da Educação Superior. No entanto, os dados encontrados nesta pesquisa demonstram que tais experiências nessas disciplinas geraram, sim, elementos que contribuíram e prepararam os BDCCs para a profissão docente.

Destacamos que, mesmo havendo pouca oferta de cursos de mes- 
trado em Contabilidade no Brasil, se comparada às outras áreas, há poucos docentes universitários, no bacharelado em Ciências Contábeis, que procuram cursos de mestrado em outras áreas (ANDERE; ARAÚJO, 2008; LAPINI, 2012), o que nos faz refletir sobre a importância de os BDCCs buscarem uma formação que os auxilie na docência.

Assim, entendemos que a formação pós-graduada nas áreas específicas vem promovendo uma preparação para que os BDCCs adquiram habilidades e competências, as quais contribuem para a segurança de sua prática docente em sala de aula (FERREIRA, 2015).

Na sequência, questionamos sobre em que a formação na pós-graduação os auxiliou, e destacamos a fala do BDCC 5: "[...] você acaba copiando os modelos de avaliação. [...] a forma que o professor atua, [...] passa a observar [...] a didática que funciona e a que não funciona. [...] então acho que acaba contribuindo, nesse sentido, [...] você vai aprendendo na observação". Assim, fica claro que os BDCCs consideram que a pós-graduação potencializa a forma de os bacharéis atuarem na docência. Entendemos que os nossos sujeitos acabam refletindo sobre sua prática, através dos exemplos vivenciados como alunos na pós-graduação, relatando que estas contribuem para sua prática, corroborando o que enfatizam Pimenta e Anastasiou (2008), Nóvoa (2011), Andere (2007), entre outros, e o que afirma Cunha (2006): a docência está permeada pelas representações sociais e significações construídas pelos docentes em suas experiências formativas, porém este não é o único cenário que esta formação ocorra, sendo importante a adoção de estratégias direcionadas para a formação dos bacharéis docentes.

\section{Atividades na docência}

Ao buscarmos entender o que dizem os BDCCs sobre suas atividades na docência e as possíveis contribuições para a pedagogia universitária, apresentamos o Quadro 1:

Quadro 01 - Atividades na Docência Universitária dos BDCCs

\begin{tabular}{|c|c|c|c|c|c|c|c|}
\hline \multirow{2}{*}{ ATIVIDADES } & \multicolumn{7}{|c|}{ SUJEITOS DA PESQUISA } \\
\cline { 2 - 8 } & BDCC 1 & BDCC 2 & BDCC 4 & BDCC 5 & BDCC 6 & BDCC 7 & BDCC 8 \\
\hline $\begin{array}{c}\text { REGIME DE } \\
\text { TRABALHO }\end{array}$ & TIDE & TIDE & TIDE & $30 \mathrm{~h} / \mathrm{a}$ & TIDE & TIDE & $30 \mathrm{~h} / \mathrm{a}$ \\
\hline ENSINO & SIM & SIM & SIM & SIM & SIM & SIM & SIM \\
\hline PESQUISA & -- & SIM & -- & -- & SIM & -- & SIM \\
\hline
\end{tabular}




\begin{tabular}{|c|c|c|c|c|c|c|c|}
\hline EXTENSÃO & SIM & SIM & SIM & -- & SIM & -- & SIM \\
\hline GESTÃO & SIM & -- & SIM & -- & -- & -- & -- \\
\hline
\end{tabular}

Fonte: Elaboração Própria, 2017, conforme dados coletados nas fichas funcionais dos sujeitos pesquisados.

Assim, quanto às atividades inerentes ao ensino, todos os BDCCs pesquisados a realizam, compreendendo uma carga horária total de 20 horas semanais, descrita Anexo I da Resolução no 007/2016 do Conselho de Ensino e Pequisa e Extensão (CONEPE) (UNEMAT, 2016). Na sequência, buscamos entender as demais atividades realizadas pelos BDCCs, em que encontram alguns entraves quanto à definição detalhada da carga horária destinada às atividades de pesquisa e extensão, e mesmo que essa Universidade tenha regulamentado tais atividades por meio desta resolução, não deixa clara a distribuição entre as atividades no regime de trabalho TIDE como estabelece no regime TP.

Para que pudéssemos confrontar os dados coletados no QC e na entrevista analisamos as fichas funcionais dos BDCCs no que se refere à realização das atividades de pesquisa e extensão. Assim, entre os sujeitos da pesquisa, três $\operatorname{BDCCs}(2,6$ e 8$)$ desenvolvem atividades de pesquisa, e cinco BDCCs $(1,2$, 4,6 e 8) desenvolvem extensão, enquanto o BDCCs (5 e 7) exerceram somente atividade de ensino, conforme quadro 01.

Nesse aspecto, percebemos algumas inconsistências nas respostas dos BDCCs quando questionados sobre o desenvolvimento das atividades de pesquisa e/ou extensão no semestre 2016/2. Alguns deles não souberam dizer em quais projetos de extensão ou de pesquisa estavam inseridos, seja na qualidade de coordenadores, membros ou colaboradores, portanto, consideramos que eles não as distinguem, corroborando os resultados da pesquisa de Ferreira (2015), que destaca que os docentes da área contábil não sabem relacionar tais atividades, e alguns consideram a pesquisa apenas um espaço para realizar leituras e estudos sistemáticos ou para manter o regime de trabalho. Além disso, o mesmo autor, constata que a pesquisa no campo da educação contábil é periférica, e esses cursos ainda se submetem ao estereótipo social enraizado ao longo dos tempos sobre a profissão ser eminentemente técnica.

Cabe ressaltar que a atividade de extensão é mais desenvolvida pelo grupo pesquisado, e deduzimos que esta lhes parece mais prazerosa e thes desperta maior engajamento por considerá-la uma forma de prestação de serviços à comunidade em geral, dado registrado no excerto da fala do BDCC 6: "[...] eu gosto muito [...] acho que ela te possibilita este contato com o externo, com o povo [...] eu acho que a gente tem que dar uma resposta, um retorno". 
Nesse sentido, diz Ferreira (2015), essa situação ocorre porque os cursos de contabilidade incorporam uma cultura dentro da visão pragmática/utilitarista.

Em relação à gestão administrativa, dois BDCCs (1 e 4) estavam desenvolvendo essa atividade, e, ao ser questionado, o BDCC 1 disse: "ela me obriga a tomar decisões [...] a analisar situações contábeis que, muitas vezes, me apoio à vivência técnica da prática apoiado pela teoria". Dessa forma, ao analisar a fala do BDCC 1 perecebe-se que este a considera uma estratégia para aprimorar e/ou incrementar sua aula, pois concilia as experiências vivenciadas na prática da função de gestor, em que correlacionamos com o que diz Ferreira (2015) ao enfatizar que tais funções acabam favorecendo e enriquecendo as aulas, devido a situações cotidianas experenciadas pelos sujeitos.

Podemos considerar que a UNEMAT deveria instituir uma forma de controle e planejamento das atividades inerentes à docência universitária, definindo claramente como estas devem ser cumpridas e acompanhadas para que realmente exista a indissociabilidade entre elas, sendo urgente a inserção de políticas internas que atendam essa fragilidade encontrada em nosso estudo.

\section{Considerações}

O desenvolvimento desta investigação nos proporcionou a compreensão do modo com que a formação e as atividades na docência são desenvolvidas pelos BDCCs da instituição pesquisada ao constatarmos que elas têm contribuído para a construção da Pedagogia Universitária no referido curso de graduação.

De modo geral, os sujeitos revelam que a pós-graduação stricto sensu da qual participaram, trouxeram contribuições essenciais para sua aprendizagem no campo da educação, em um movimento permanente e contínuo de reflexão sobre seus modos de ensinar e aprender, considerando-o um processo essencial para a construção da Pedagogia Universitária no bacharelado. Destacam também que, mesmo as atividades na docência sendo realizadas nas áreas específicas da contabilidade, trazem para os BDCCs elementos formativos que os ajudam a repensar sua prática docente, na percepção da necessidade de manter uma atitude crítica e dialógica perante seus estudantes e demais atores do cenário universitário.

Em relação às atividades inerentes à docência na universidade, constatamos que todos os BDCCs realizaram a atividade de ensino, pela sua obrigatoriedade. Em relação às demais atividades, constatamos que os BDCCs não as desenvolvem como forma de produção de conhecimento, por considerarem 
a pesquisa apenas um espaço para realizar leituras e estudos sistemáticos ou para manter o regime de trabalho. E ainda, percebemos na análise da Resolução no 007/2016 CONEPE, não apresenta uma definição detalhada da carga horária destinadas às atividades, ocasioando um melhor acompanhamento ou controle de tais atividades.

Enfim, os dados coletados sinalizam a existência da Pedagogia Universitária dos BDCCs, os quais, desde o início da investigação, mostraram-se abertos para o diálogo e o aprendizado do que apresentamos como proposta de estudo, em que trazemos como proposta para a inserção de um programa de Pedagogia Universitária como um espaço formativo, construído de forma coletiva e dialogicamente, a ser realizado de forma permanente. Temos, desse modo, o intuito de que o docente conheça a universidade, seus objetivos, estrutura, metas a serem alcançadas, como forma de receber os novos docentes que ingressam na IES, mas também acompanhar e incentivar os que já estão atuando nela. E, além disso, discutir e melhorar a regulamentação das atividades de pesquisa e extensão, essenciais para a existência e sustentação da universidade.

Encerramos nossa pesquisa com a satisfação de ter contribuído para a inserção do campo da Pedagogia Universitária junto ao curso de Ciências Contábeis, com a esperança de que esta possa se espalhar para os demais cursos, e, no futuro, seja transformada em política interna da instituição pesquisada.

\section{Referências}

ANDERE, Maira Assaf. Aspectos da formação do professor de ensino superior de Ciências Contábeis: uma análise dos programas de pós-graduação. Dissertação (Mestrado). Faculdade de Economia, Administração e Contabilidade de Ribeirão Preto Universidade de São Paulo - USP, Ribeirão Preto-SP, 2007.

ANDERE, Maira Assaf; ARAÚJO, Adriana Maria Procópio de. Aspectos da formação do professor de ensino superior de Ciências Contábeis: uma análise dos programas de pós-graduação. Revista Contabilidade e Finanças, São Paulo, v. 19, n. 48, 2008. p. 91-102.

BARDIN, Laurence. Análise de conteúdo. Lisboa: Edições 70, 2006.

BEHRENS, Marilda Aparecida. Docência universitária: formação ou improvisação? Revista Educação, Santa Maria, v. 36, n. 3, p. 441-454, set/dez., 2011. 
BITENCOURT, Loriége Pessoa. Pedagogia Universitária potencializada no diálogo reflexivo sobre educação matemática: quando três gerações de educadores se encontram. Tese (Doutorado). Faculdade de Educação. UFRGS, Porto Alegre, RS, 2014.

BITENCOURT, Loriége Pessoa. Aprendizagem da docência do professor formador de educadores matemáticos. Curitiba: CRV. 2017.

BITENCOURT, Loriége Pessoa; ZART, Laudemir Luiz. Os educadores na educação do campo e suas condições de trabalho docente. Revista Brasileira de Educação do Campo, v. 2, n.1 jan/junho, 2017. p. 252-274,

BOGDAN, Robert C.; BIKLEN, Sari K. Investigação qualitativa em educação. Uma introdução à teoria e aos métodos. Portugal: Porto. 1994.

BRASIL. Lei no 9.394, de 20 de dezembro de 1996: Diretrizes e Bases da Educação Nacional. Brasília, (1996). Disponível em: <http://www.planalto.gov.br/ ccivil_03/Leis/L9394.htm>. Acesso em: 22 set. 2014.

BRASIL. Censo da educação superior. Notas Estatísticas - INEP, 2016. Disponível em: <http://download.inep.gov.br/educacao_superior/censo_superior/ documentos/2016/notas_sobre_o_censo_da_educacao_superior_2016. pdf>. Acesso em: 09 nov. 2017.

COIMBRA, Camila Lima; FELÍclo, Helena Maria dos Santos. A formação do docente universitário: estatuto legal, políticas e perspectivas atuais. In: ABRAMOWICZ, Mere et. al. A construção do saber docente por bacharéis no ensino superior: desafios de uma formação/organização. Curitiba: CRV. 2015.

COUTO, Ligia Paula. A Pedagogia Universitária nas propostas inovadoras de universidades brasileiras: por uma cultura da docência e construção da identidade docente. 188f. Tese (Doutorado). Programa de Pós-Graduação em Educação. Faculdade de Educação da Universidade de São Paulo. 2013.

CUNHA, Maria Isabel da. Docência na universidade, cultura e avaliação institucional: saberes silenciados em questão. Revista Brasileira de Educação, v. 11, n. 32, UNISINOS. 2006.

CUNHA, Maria Isabel da. O bom professor e sua prática. 6a ed. Campinas: Papirus. 1996.

CUNHA, Maria Isabel da. Trajetórias e Lugares de Formação da Docência Universitária: da perspectiva individual ao espaço institucional. Araraquara: Junqueira\&Marin: Brasília - DF: CAPES: CNPq. 2010. 
FERREIRA, Marcelo Marchine. Docência no Ensino Superior: aprendendo a ser professor de contabilidade. 2015. 168f. Tese (Doutorado). Programa de Pós-Graduação em Educação da Faculdade de Educação. UFSCAR. São Carlos-SP. 2015.

FONSECA, João José Saraiva. Metodologia da pesquisa científica. Fortaleza: UEC. 2002.

FRANCO, Maria Estela Dal Pai; KRAHE, Elizabeth D.. Pedagogia Universitária na UFRGS: espaços de construção. In: MOROSINI, Marilia Costa et al.. Enciclopédia Universitária. Porto Alegre: FAPERGS/RIES. 2003.

FREIRE, Paulo. Pedagogia da autonomia: saberes necessários à prática educativa. São Paulo: Paz e Terra. 1996.

GONÇALVES, Rosilene Nogueira; GASPARIN, João Luiz. Formação Pedagógica do profissional bacharel em Ciências Contábeis e sua ação docente do ensino superior. Seminário de Pesquisa do PPE. Maringá. 2013.

IMBERNÓN, Francisco. Formação docente e profissional: formar-se para a mudança e a incerteza. 3a ed. São Paulo: Cortez. 2002.

ISAIA, Silva Maria de Aguiar. Desafios à docência superior: pressupostos a considerar. In: RISTOFF, Dilvo.; SEVEGANANI, Palmira. Docência na Educação Superior, Brasília, Instituto Nacional de Estudos e Pesquisas Educacionais “Anísio Teixeira", v. 5. 2006.

LAFFIN, Marcos. De Contador a professor: a trajetória da docência no ensino superior de contabilidade. 203f. 2002. Tese (Doutorado). Faculdade de Engenharia de Produção. Universidade Federal de Santa Catarina - UFSC, Florianópolis-SC. 2002.

LAPINI. Vivian Carolina. Panorama da formação do professor em Ciências Contábeis pelos cursos stricto sensu no Brasil. 2012. 78f. Dissertação (Mestrado). Faculdade de Economia, Administração e Contabilidade de Ribeirão Preto Universidade de São Paulo - USP, Ribeirão Preto-SP, 2012.

LEITE, Denise Bailarine C. Pedagogia Universitária (verbete). In: MOROSINI, M. (Eds.). Enciclopédia de Pedagogia Universitária - Glossário. Brasília: INEP. 2006.

LÜDKE, Marli; ANDRÉ, Menga. A pesquisa em Educação: abordagens qualitativas. São Paulo: EPU. 1986. 
MARCELO GARCIA, Carlos. Formação de Professores: para uma mudança educativa. Portugal: Porto. 1999.

MOROSINI, Marilia. Professor do Ensino Superior: identidade, docência e formação. Org. Brasília: Instituto Nacional de Estudos e Pesquisas Educacionais. 2000.

NOSSA, Valcemiro. Ensino da Contabilidade no Brasil: uma análise crítica da Formação do Corpo Docente. USP: São Paulo. 1999.

NÓVOA, Antonio. O regresso dos professores. Pinhais: Melo. 2011.

PACHANE, Graziela Giusti. Formação de Professores para a docência universitária no Brasil: uma introdução histórica. Aprender. Cad. de Filosofia e Psic. da Educação, Ano VII - n. 12, Vitória da Conquista/BA. 2009.

PIMENTA, Selma Guarrido; ANASTASIOU, Léa das Graças Camargos. Docência no Ensino Superior. São Paulo: Cortez, 2002.

PIMENTA, Selma Guarrido; ANASTASIOU, Léa das Graças Camargos. Docência no Ensino Superior. São Paulo: Cortez. 2008.

RIBEIRO, Tatiana Rosa Carvalho. A Pedagogia Universitária do Bacharel Docente no Curso de Ciências Contábeis: ênfase na Formação e Atividades na Docência. 2018. 169 f. Dissertação (Mestrado Acadêmico). Curso de Pós-graduação Stricto Sensu em Educação, Faculdade de Educação e Linguagem, Câmpus de Cáceres, Universidade do Estado de Mato Grosso, 2018.

ROVEDA, Patricia de Oliveira; MIOLO, Silvana Basso. (2017). Formação Docente para o ensino superior e as estratégias de ensino-aprendizagem de professores licenciados e bacharéis. In: BRANCHE, Vandoir Roberto; OLIVEIRA, Valeska Fortes de. (Orgs.). Formação de Professores em tempos de incertezas: imaginários, narrativas e processos autoformadores. Jundiaí: Paco Editorial, 2017. p. 71-91.

SAVIANI, Dermeval. Educação em diálogo. Campinas: Autores Associados. 2011.

SLOMSKI, Vilma Geni et al. Saberes que fundamentam a prática pedagógica do professor de ciências contábeis. São Paulo: FEA/USP. 2008.

SOARES, Sandra Regina; CUNHA, Maria Isabel da. Formação do Professor: a docência universitária em busca de legitimidade. Salsoavador. EDUFBA. 2010. 
SOUZA, J. A. e; MENDONÇA, D. J. Considerações sobre formação pedagógica de docentes para o curso de Ciências Contábeis. REGS, Faculdade Eça de Queirós, no 21, 2016.

TARDIF, M. O trabalho docente: elementos para uma teoria da docência como profissão de interações humanas. 3 Ed. Petrópolis, RJ, Vozes, 2007.

UNEMAT. Lei Complementar $n^{\circ} 320$ de 30 de junho de 2008. Plano de Carreira dos Docentes da Educação Superior da Universidade do Estado de Mato Grosso. 2008. Disponível em: <http://www.unemat.br/reitoria/assoc/docs/ legislacao/lei_complementar_320_2008.pdf>. Acesso em: 05 jul. 2017.

UNEMAT. Resolução $n^{\circ}$ 007/2016-CONEPE. Regula o acompanhamento das atividades nas Leis Complementares N³20/2008 e N534/2014. 2016. Disponível em: <http://www.unemat.br/resolucoes/resolucoes/conepe/3481_ res_conepe_7_2016.pdf>. Acesso em: 05 jul. 2017.

VASCONCELOS, Maria Lucia M. Carvalho. A formação do professor do ensino superior. Niterói: Intertexto; São Paulo: Xamã, 2009.

VOLPATO, Gildo. Profissionais Liberais Professores: aspectos da docência que se tornam referência na educação superior. Curitiba, Editora CRV. 2010.

YIN, Robert. K. Estudo de Caso - Planejamento e Métodos - 4ạ ed. Porto Alegre: Bookman. 2010. 